\title{
THE EFFECT OF SURFACE TREATMENTS ON NANOHARDNESS OF 316L STAINLESS STEEL
}

\author{
${ }^{1}$ Mariia ZIMINA, ${ }^{1}$ Leoš KŘIVSKÝ \\ ${ }^{1}$ Research Center Řež Ltd., Husinec, Czech Republic, EU, mariia.zimina@cvrez.cz
}

https://doi.org/10.37904/metal.2021.4139

\begin{abstract}
The effect of surface treatments on mechanical properties and corrosion resistance of most engineering steels is the object of a significant number of studies. It is known that surface machining can affect the steel local mechanical properties and, thus lead to the premature cracking under certain conditions. During surface treatment, significant amount of local shear stress can be imposed into the subsurface area of material. The depth of this locally deformed zone, as well as its properties, can vary according to the treatment conditions. This study is focused on the correlation of microstructure and nanohardness in the $316 \mathrm{~L}$ austenitic stainless steel with variation of surface treatment conditions.
\end{abstract}

Keywords: Stainless steel, nanoindentation, hardness, microstructure

\section{INTRODUCTION}

$316 \mathrm{~L}$ austenitic stainless steel (SS) is widely used in a variety of applications providing high corrosion and high temperature properties. Due to low carbon contain $(0.018-0.030 \mathrm{wt} \%) 316 \mathrm{~L}$ SS has increased resistivity to pitting and intergranular corrosion even in concentrated acids. Thanks to favourable corrosion properties it finds its application in the chemical industry, medicine and generally in low chloride saturated water environments [1].

Final product's surface can be subjected to surface treatment, in order to improve mechanical properties or corrosion resistance of the material. The benefits of mechanical (e.g. milling) surface treatment are lower surface roughness, impurities removal or hardness increase. These adjustments provide better protection from mechanical damage and can significantly improve corrosion resistance thanks to removing defects and cracks from manufacturing process, e.g. in welding affected areas. Described manufacturing defects can serve as corrosion initiation sites in water environments causing pitting, intergranular corrosion or environmentally assisted cracking $[2,3]$.

Measuring mechanical properties such as hardness or Young Modulus of thin machined layers is complicated due to their small scale. Interaction volume of affected material limits tip loading during indentation and hardness measurement. Thus, the nanoindentation appears to be a reasonable method. Applied load can reach from tens of $\mathrm{nN}$ up to hundreds of $\mathrm{mN}$. Unlike hardness or microhardness measuring indents diagonals/diameters, unloading curve analysis is executed to calculate material hardness and other parameters such as Young Modulus and reduced Young modulus. It requires very sensitive piezoelectric transducer with extended tip and elimination of disturbing vibrations [4].

Direct indentation to the machined layer is not an optimal solution when trying to eliminate the influence of the bulk material. Cross section indentation from layer to bulk material is better solution proves to be a better solution. Although nanoindentation offers large scale of loads, small indents as result of $\mathrm{nN}$ or $\mu \mathrm{N}$ can affect correct unloading curves calculations while the indenter tip is used up or damaged [5]. On the contrary, large indent can cover larger area of the machined layer. Various loads were tested to optimise the maximal load and indents size for Berkovitch sapphire tip on 316L SS. All measurements were conducted with similar load 
and loading function and indents matrix, and analysed with the same software. Indents were then observed by means of scanning electron microscopy (SEM) and electron back-scattered diffraction (EBSD) mapping was conducted to analyse microstructure and compare it with nanoindentation distribution results.

\section{MATERIAL AND EXPERIMENTAL TECHNIQUES}

\subsection{Material}

The 316 LS produced by ENSA with the chemical composition shown in Table 1 was used for the microstructural analysis and nanoindentation. The 316L SS plate was cold rolled along the $\mathrm{L}$ direction (Figure 1) with an Acerinox rolling machine with a $15 \%$ thickness reduction. After cold rolling, the L-T surface was machined using three industrial surface machining by the Nuclear Advanced Manufacturing Research Centre (NAMRC): a) standard treatment industrial (STI), b) surface advanced machining 1 (SAM1), c) surface advanced machining 2 (SAM2).

The STI machining was performed by flat milling with feed speed of $300 \mathrm{~mm} / \mathrm{min}$, a cut depth in between 0.6 and $1 \mathrm{~mm}$ and with a rotation speed of 200 RPM. SAM1 and SAM2 were machined with a cut dept of $1 \mathrm{~mm}$ with a feed speed of $0.4 \mathrm{~mm} /$ tooth and a cutting speed of $210 \mathrm{~m} / \mathrm{min}$. The difference between SAM2 and SAM1 is the usage of supercritical $\mathrm{CO}_{2}$ with the addition of $1 \mathrm{ml} / \mathrm{min}$ of soybean oil as a lubricant in SAM2 instead of the $\mathrm{CO}_{2}$ in SAM1
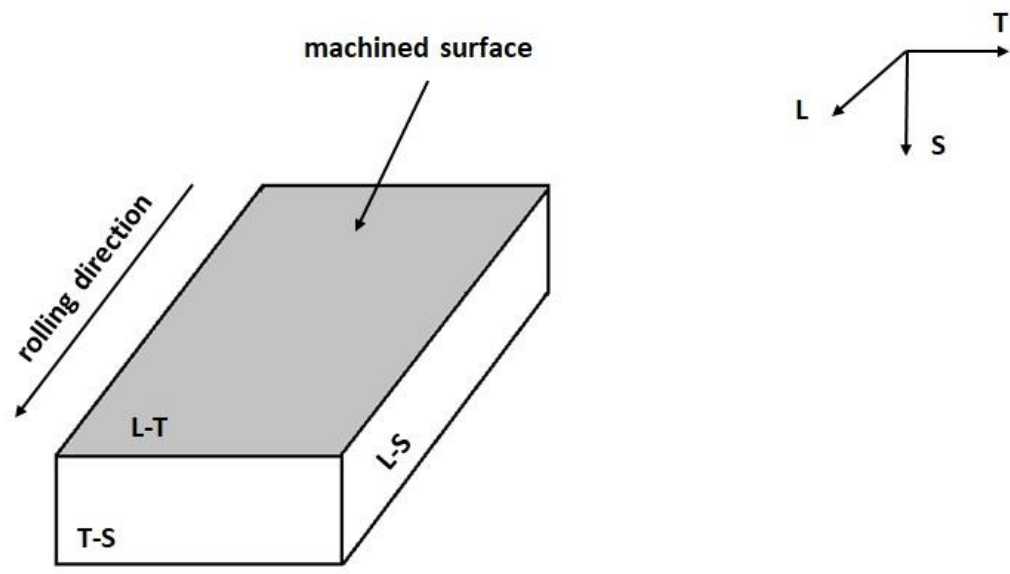

Figure 1 Schematic image of the orientation of the applied machining to the $316 \mathrm{~L}$ SS plate

Table 1 Chemical composition in wt\% of cold-rolled 316 L stainless steel.

\begin{tabular}{|c|c|c|c|c|c|c|c|c|c|c|c|c|}
\hline B & C & Co & Cr & Cu & Fe & Mn & Mo & N & Nb & Ni & P & S \\
\hline 0.0004 & 0.018 & 0.01 & 17.56 & 0.05 & 66.04 & 1.72 & 2.33 & 0.07 & 0.01 & 12.17 & 0.017 & 0.001 \\
\hline
\end{tabular}

Specimens for microstructural characterization of L-S cross-sections were cut from the $316 \mathrm{~L}$ plate using highspeed cutting wheel. The specimens were subsequently ground with $\mathrm{SiC}$ paper and polished using $3 \mu \mathrm{m}$ and $1 \mu \mathrm{m}$ diamond solutions and $\mathrm{SiO}_{2}$ suspension as a final step.

\subsection{Characterization}

Nanoindentation measurements were first conducted on sub-surface regions of all the samples and further correlated to the microstructure using SEM. 


\subsubsection{Nanoindentation}

The nanoindentation measurements were performed using Hysitron TI 950 nanoindention device equipped with sapphire Berkovich indenter. The area function of the indenter was calibrated by the fused quartz with known elastic modulus and hardness, whereas the optical instruments and the tip accuracy were calibrated with a Poly-(methyl methacrylate) (PMMA) or acrylic glass. A trapezoid load function with maximum load of 3 $\mathrm{mN}$ was used, where the load was increased for $3 \mathrm{~s}$ to the maximal force, paused for $2 \mathrm{~s}$ to eliminate contribution of the elastic deformation and, finally unloaded in $3 \mathrm{~s}$. The thermal drift and piezo instrument settle were automatically calculated before every single indentation step and considered in the calculations.

The nanoindentation maps in L-S plane with $25 \times 12$ individual indents separated by $10 \mu \mathrm{m}$ along the Ldirection and $5 \mu \mathrm{m}$ on the S-direction covered the area of $240 \times 55 \mu \mathrm{m}^{2}$. Nano - hardness $(\mathrm{nH})$ was calculated and $\mathrm{nH}$ distribution maps of the chosen sub-surface regions of $30 \times 30 \mu \mathrm{m}$ with the first row of indents closest to the surface were further analysed.

\subsubsection{SEM}

EBSD analyses were performed at $20 \mathrm{kV}$ with a TESCAN Lyra field emission gun scanning electron microscope (FEG-SEM), equipped with a EBSD detector and a SDD X-Max 150. The samples were tilted at $70^{\circ}$ with the respect to the incident electron beam and EBSD maps of $30 \times 30 \mu \mathrm{m}^{2}$ were acquired with a step size of $50 \mathrm{~nm}$. Ol Aztec ver. 5.0 software was used for data processing and analysis.

\section{RESULTS AND DISCUSSION}

$15 \%$ cold-rolled 316 L austenitic SS microstructure is shown in Figure 2. The average grain size in the bulk of the plate is around 40 um observed in T-S plane. Extensive plastic deformation is imposed during cold-rolling as is indicated by twins and slip bands in inverse pole figure (IPF) in Figure 2a. Local misorientaton mapping (Figure 2b) shows high misorientation on the grain boundaries of initial grains as well as grains formed during cold rolling. This indicates the high level of deformation induced during cold processing.
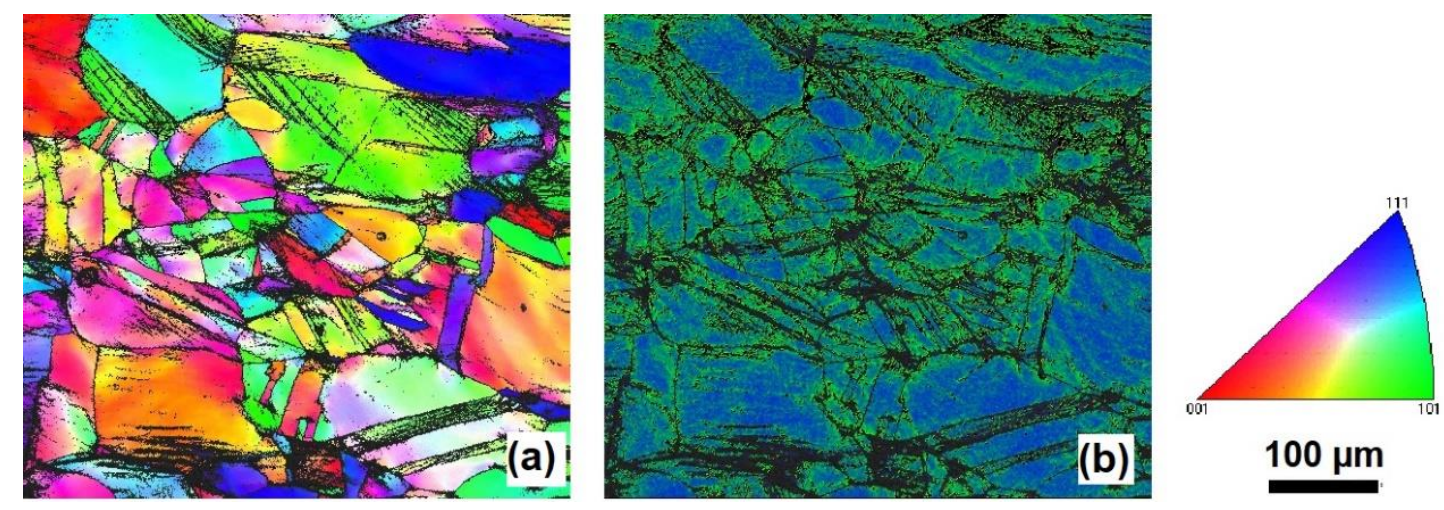

Figure 2 Microstructure of the col-rolled 316L stainless steel: a) IPF and b) local misorientation maps.

The subsurface microstructure was studied using a combination of nanohardness and EBSD analysis, by direct correlation of local mechanical properties with microstructural features. In Figure 3, the distribution of the nanohardness along the depth of the studied subsurface regions of three machined surfaces is presented. Nano-hardness values are averaged from three values for each row of indents starting with the closest one to the surface and covering a depth of about $30 \mu \mathrm{m}$.

In the rolling direction, the ultrafine grain layer (with the grain size less than $50 \mathrm{~nm}$ ) of 1-4 $\mu \mathrm{m}$ is observed in all machined samples. The hardness is significantly higher in this area due to a significantly small grain size, less than $50 \mathrm{~nm}$. The grain size was determined according to the step size of acquired diffraction patterns 
since the precise value cannot be distinguished using conventional EBDS with limited resolution. Figures $\mathbf{3 g}-\mathbf{3} \mathbf{i}$ show that in all machined samples a subsurface layer with increased hardness is formed. For STI surface UFG layer is slightly thinner compared to SAM samples (Figure 3a). However, according to the nano-hardness data in Figure $\mathbf{3 g}$, the machining affected area for SAM2 samples is deeper and might be as deep as $15 \mu \mathrm{m}$. The nanohardness in this area achieves about $4.5 \mathrm{GPa}$ and then decreases to about $4 \mathrm{GPa}$ with distance from the surface. Such a decrease of hardness might be also caused by the grain orientation as is shown in Figure 3a. However, the local misorientation map in Figure $\mathbf{3 b}$ shows larger misorientation in the substructure, which indicates the higher amount of local strain, caused by induced plastic deformation.

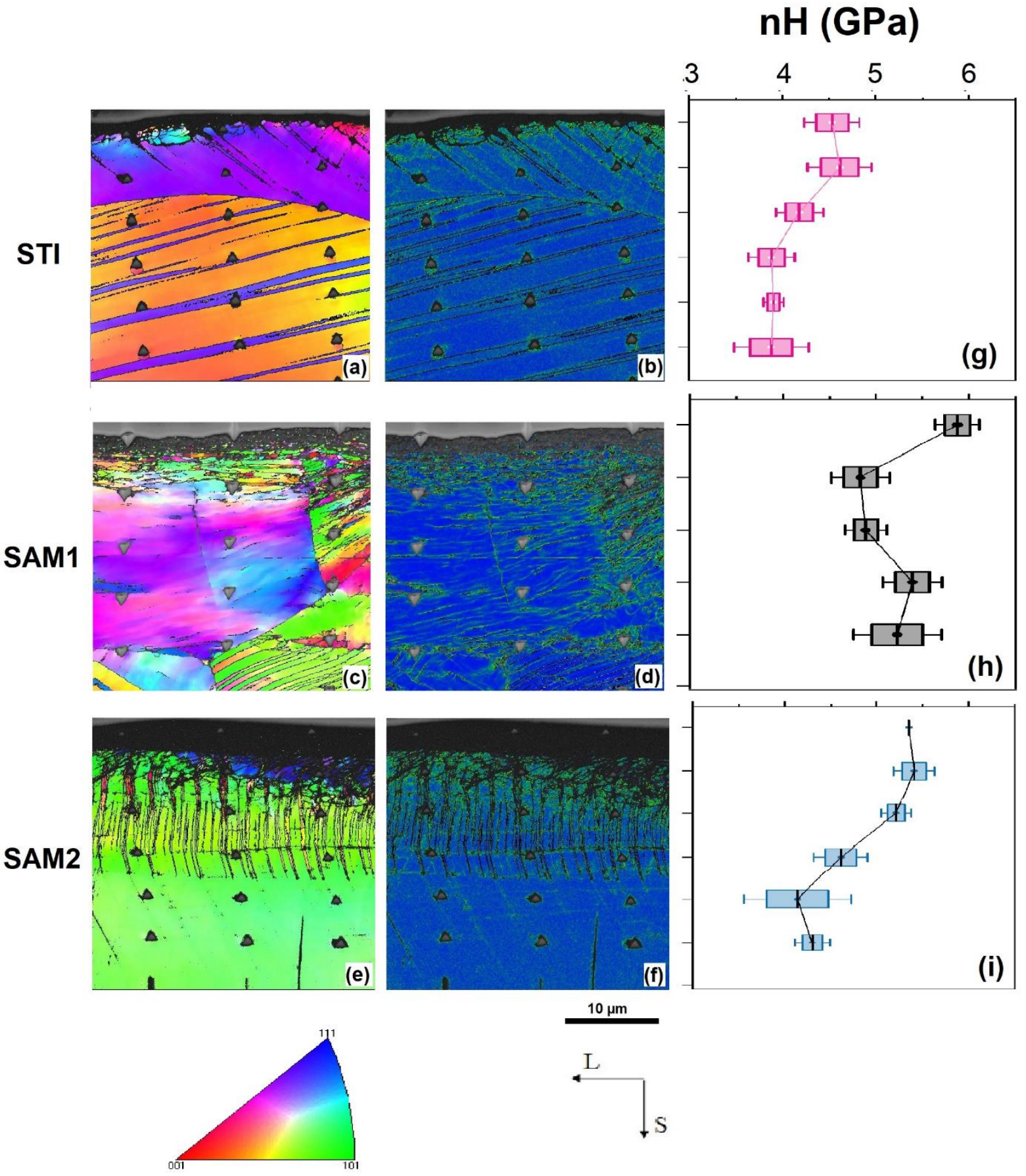

Figure 3 Electron-back scattered diffraction maps (IPF and local misorientation) and nanoindentation average value per row of indents for STI, SAM1 and SAM2 machined surfaces in L-S plane. 
SAM1 cross-section in the rolling direction shows higher hardness values in $30 \mu \mathrm{m}$ subsurface area compared to STI. The hardness of UFG layer is reaching $6 \mathrm{GPa}$ and decreases to about $5 \mathrm{GPa}$ in $10 \mu \mathrm{m}$ (Figure h). EBSD mapping of this area also shows a highly deformed area on the right-hand side in Figure $\mathbf{3} \mathbf{c}$ and $\mathbf{3 d}$, which can be caused by non-uniform application of the machining tool. This leads to the higher level of induced strain in the grain on the left according to Figure 3d. These two neighbouring grains have slightly different hardness, which leads to the lower average value compared to indents row 4 and 5, lying 15 and $20 \mu \mathrm{m}$ from the surface respectively. SAM2 subsurface area IPF map in Figure 3e shows the presence of UFG layer of about $4 \mu \mathrm{m}$. This region is followed by the $2-5 \mu \mathrm{m}$ sub-grains region produced by dynamic recrystallisation during machining. A high level of induced deformation is also present as shown by the presence of extensive twinning and increased local misorientation up to $20 \mu \mathrm{m}$ deep. The nanohardness is $5.3 \mathrm{GPa}$ in the UFG layer, it slightly increases in the sub-grained region and decreases up to $25 \mu \mathrm{m}$ depth. This behaviour is in very good agreement with the observed microstructure.

The thickness of UFG layer increases from STI to SAM1 and SAM2. The SAM1 and SAM2 surfaces were machined using a tool with larger cut depth of $1 \mathrm{~mm}$ compared to STI. The addition of the soybean oil to the $\mathrm{CO}_{2}$ as a lubricant might be one of the reasons for the production of a thicker UFG surface layer in SAM2 compared to SAM1. Slightly lower nanohardness in UFG layer compared to the deeper regions was observed in both STI and SAM2 samples. This can be caused by two main reasons. Firstly, it can be due to the low amount of data points and insufficient statistics. Secondly, it can be related to the procedure of nano-hardness evaluation. As it was discussed in [6] by Musil et al., strain hardening characteristics should also be taken into an account. In fact, according to them, the ratio $\mathrm{H} / \sigma_{\mathrm{y}}$, where $\sigma_{\mathrm{y}}$ is yield strength, ranges, respectively, from 2.2 to 2.6 or 2 to 20 (for indentations with a cone angle of $70.3^{\circ}$ ). Moreover, for some hard thin coatings (but $<50$ $\mathrm{GPa}$ ) this effect was discussed and addressed to the procedure of nano-hardness and, the so-called, universal hardness $(\mathrm{HU})$ evaluation. This effect should be further studied.

\section{CONCLUSIONS}

The effect of machining on sub-surface microstructure of cold-worked 316L SSs was studied. Three different surface machining were compared (STI, SAM1 and SAM2). The cross-sections of the samples in the L-S plane were analysed using nanoindentation and EBSD mapping. The results show that the thickness of UFG layer formed on the surface changes with different machining techniques. The UFG layer thickness increases from STI to SAM1 and further to SAM2. The possible reason is that the SAM1 and SAM2 surfaces were machined using a tool with larger cut depth of $1 \mathrm{~mm}$ compared to STI. The addition of the soybean oil to the $\mathrm{CO}_{2}$ as a lubricant can lead to a production of thicker UFG surface layer in SAM2 compared to SAM1. In all samples the UFG layer is characterized by having the highest nano-hardness. This work is still ongoing in the frame of HORIZON-2020:MEACTOS project.

\section{ACKNOWLEDGEMENTS}

The authors would like to acknowledge the European Horizon 2020 MEACTOS with grant No. 755151 for the financial support, the Equipos Nucleares S.A. (ENSA) to have provided the material and the Advanced Manufacturing Research Centre (ANMRC) to have provided the machining surface on the material used in this study.

\section{REFERENCES}

[1] CRAMER, S.D., COVINO, B. S., Jr. ASM Handbook Volume 13B, Corrosion: Materials. Ohio: ASM International, 2005 
[2] COELHO, L.B., KOSSMAN, S., MEJIAS, A., NOIRFALISE, X., MONTAGNE, A., VAN GORP, A., POORTEMAN, M., OLIVIER, M.-G. Mechanical and corrosion characterization of industrially treated $316 \mathrm{~L}$ stainless steel surfaces. Surface and Coatings Technology. 2020, vol. 382, pp. 1-9.

[3] BALUSAMY, T., SANKARA NARAYANAN, T.S.N., RAVICHANDRAN, K., SONG PARK, I., MIN HO, L. Influence of surface mechanical attrition treatment (SMAT) on the corrosion behaviour of AISI 304 stainless steel. Corrosion Science. 2013, vol. 74, pp. 332-344.

[4] ZHONG, H. Chapter 6 - Characterization of Materials, Nanomaterials, and Thin Films by Nanoindentation. Microscopy Methods in Nanomaterials Characterization. Amsterdam: Elsevier, 2017, pp. 165-239.

[5] PACKARD, C.E., TRENKLE, J.C., SCHUH, C.A. Nanoindentation: High Temperature. In: Encyclopedia of Materials: Science and Technology. 2010, pp 1-6.

[6] MUSIL, J., KUNC, F., ZEMAN, H., POLÁKOVÁ, H. Relationships between hardness, Young's modulus and elastic recovery in hard nanocomposite coatings. Surface and Coatings Technology. 2002, vol. 154, pp. 304-313. 